\title{
Research on Exhibition Evaluation Based on 400 Exhibition Economy Information Journal
}

\author{
Chuanhong $\mathrm{Xu}^{1} \&$ Jing $\mathrm{Li}^{1}$ \\ ${ }^{1}$ Shanghai University of Engineering Science, China \\ Correspondence: Jing Li, Shanghai University of Engineering Science, China. E-mail: ljing1990318@126.com \\ Received: July 07, 2014 \\ Accepted: July 21, 2014 \\ Online Published: July 25, 2014 \\ doi: 10.5430/bmr.v3n3p20 \\ URL: http://dx.doi.org/10.5430/bmr.v3n3p20
}

\begin{abstract}
Along with the development of Chinese exhibition economy, convention and exhibition industry get more and more attention of experts and scholars, the research achievements of the exhibition economy has countless. In this paper, the authors use 400 exhibition economy information journals, the exhibition, in terms of assessing statistics and will present the related results. The trace of the process, this paper first exhibition evaluation research in China in recent years are reviewed, and then evaluate the exhibition are summarized, and then comb when the current assessment of present situation and the period of exhibition economy the assessment of the status quo through "400 Chinese Exhibition Economy Information Journal", and the problems existing in the evaluation of combing the exhibition puts forward relevant policy suggestions.
\end{abstract}

Keywords: Exhibition, Assessment, Status quo

\section{Introduction}

In recent years, with the development of Chinese exhibition industry development, as "smokeless industry" of the convention and exhibition industry has a pivotal position on the economic development of China, but the lack of industry standards has become the bottleneck of restricting its development. At present, Chinese exhibition industry standardization work has just started. It is far from form to guide industry practice standard system and it is not conducive to sustained and healthy development of the convention and exhibition industry. In view of this, this article system through understanding research dynamic exhibition evaluation at home and abroad, and the 400 exhibition economy information journals are combed to explore the current status quo of exhibition evaluation and countermeasure analysis. It also provides some references for the development of Chinese exhibition industry standardization construction and using for reference. Specific writing ideas of this article: first of all to about the document of exhibition evaluation in recent years, and then by looking for related website statistics out the exhibition evaluation aspects of laws and regulations in our country, then a census of 400 Chinese exhibition journal comb, in turn, can according to the result of combing to understand the current status quo of exhibition evaluation in our country, finally give relevant policy recommendations.

\section{Literature Reviews}

The current literature review status quo of exhibition evaluation specific as follows:

Gopalakrishna and Williams (1992) using the intention to purchase the number of audience and plans to buy audience ratio as a fair benefit measurement; Williams (1993) with the attraction of the booth and the number of spectators at the booth contact as a measurement index, including booth appeal refers to the number of viewers are interested to visit companies booth (Srinath Gopalakrishna \& Jerome, 1992). D.Williams Gopalakrishna and Lilien (1995) with the actual audience at the booth contact ratio as a performance measurement index of the exhibition. Cavanaugh, (1976) pointed out that by visiting the booth of the audience, to achieve the intention of clinch a deal amount, the cost of each visitor, every intention of cost as a fair benefit evaluation index; Dekimpe (1997) show performance is measured with the audience appeal, specific refers to visited the booth or took the information of the target audience, claiming that visitors are interested in the product ratio (Gopalakrishna S, Lilien G L, Williams JD \& Sequeria I K, 1995). Kerin and Cron (1987) the research achievements of the attention, they raised from sales and non-sales activity for the exhibition, the concept of performance evaluation framework and experimental verification, the empirical study shows that enterprises, marketing manager of the sales behavior performance evaluation is much higher than sales behavior, suggests that only sales behavior assessment performance measure is inappropriate. 
Hansen (2004) to build a set of connotation broader exhibition benefit evaluation system, from the sales behavior, information gathering, image promotion behavior, relationships behavior, employee motivation behavior based comprehensive factors such as building assessment business exhibition performance, the concept of fuzzy model, and using the method of empirical verify validity and reliability of the model. In terms of performance evaluation (Hansen K, 2004), Hansen to build a set of connotation broader exhibition benefit evaluation system, from the sales behavior, information gathering, image promotion behavior, relationships behavior, employee motivation behavior based comprehensive factors such as building assessment business exhibition performance, the concept of fuzzy model, and using the method of empirical verify validity and reliability of the model.

Convention and exhibition research leader Liu Songping Guangzhou university (2004) summarized the American exhibition is the most important in the quality evaluation index of 16 and its magnitude, the exhibition is the most important evaluation criteria "the proportion of participation in the enterprise the decision makers", "exhibitors ratio in the target market", "the number of exhibitors," while China exhibition will pay more attention to "the number of enterprises", "exhibition area", "professional audience" and "the turnover and intention to turnover" indicator. In contrast, American exhibition evaluation system more mature, but is not suitable for China's exhibition evaluation, it is associated with the stage of China's exhibition industry development, also related to the current China's convention and exhibition to assess the demand of the market to (Liu Songping, 2004). Qian Mengxiang (2007) in the exhibition industry in Jiangsu province service standard system including basic standards, facilities, service standards and methods, but too general and summary, only qualitative, lack of convincing (Qian Mengxiang, 2007). Evaluate the concept and connotation of exhibition: Chen Zeyan (2007), only the "exhibition project assessment" this concept, simple sums up the three main types of conference and exhibition project assessment (Chen Zeyan, 2007).

$\mathrm{Ma} \mathrm{Na}(2008)$ to the exhibition industry, such as new orientation, namely the juxtaposed with tourism, trade, finance and other category of a service industry, and based on this, advances to construct the standard system: exhibition standards system including basic standards, technical standard, management standards, service standards, information standards, safety and health standards, environmental protection standards ( $\mathrm{Ma} \mathrm{Na}$, Shao Qiyong \& Yan Shaoqing, 2008). Yang jie (2009), such as the empirical study on July 11, 2007 the sixth China (Shanghai) international electronics industry exhibition, and using the IPA analysis from exhibitors both expect demand actual perception of the exhibition in combination with analysis of the importance of the main factors affecting the exhibition (Yang jie \& Gu yingkang, 2009). Chen Jing (2009) points out that the evaluation index system of city exhibition contents by the convention and exhibition environment, their achievements in exhibition and conference and exhibition effect of three parts (indicators), preliminary explored the city exhibition evaluation system contains primary, secondary and tertiary indexes, quantitative description, focused on how to use five score way combining expert meeting method, Delphi method, quantitative indicators into form of quantitative assessment(Jing Chen, 2009).

Cai Libin (2009), such as comparative analysis of the special project evaluation and the generalized definition of project evaluation, and combining with the related concepts of convention and exhibition, finally it is concluded that the concept of exhibition evaluation (Cai Libin \& Tang Yuanyuan, 2009). Chen Jing (2009) points out that the exhibition evaluation should not be limited to the review of individual exhibition projects, or conference and exhibition organizers, also put forward to build the city exhibition evaluation system, so that the whole city's exhibition industry development situation of comprehensive evaluation, to expand the concept of "assessment of the exhibition", covers the city exhibition evaluation system, explains the exhibition evaluation from a new Angle (Jing Chen, 2009). Yang Fangping (2010) to build the evaluation index system of brand exhibition, and using the AHP analytic hierarchy process (AHP) parsing the level of the evaluation index and weight (Yang jie \& Gu yingkang, 2009).

Overall, the current domestic exhibition still is exhibition project evaluation research aspects of the assessment, and the "exhibition, conference". To sum up, although at present our country has many scholars studied on exhibition evaluation, it has not formed a set of reasonable and effective evaluation system to regulate the development of exhibition industry. To this, the author will be on the basis of many scholars' studies and use the existing 400 exhibition journal of current research on exhibition evaluation of Chinese exhibition industry.

\section{Overviews}

\subsection{Exhibition Evaluation Means}

Exhibition evaluation refers to the purpose and according to certain standard, follow certain principles, using the scientific method, the exhibition activities of the various elements and its social and economic benefit for the evaluation of quality and quantity of integrated activities. Exhibition evaluation includes broad sense and narrow 
sense explain, general exhibition evaluation including exhibition evaluation of two macroscopic and microscopic levels, and exhibition, exhibition and convention after the assessment before the three stages; and special exhibition evaluation is the value of a single microscopic exhibition project evaluation.

\subsection{The Purpose of Fair Evaluation}

For different object of evaluation subject and evaluation assessment purposes are different. For conference and exhibition organizers, exhibition evaluation in order to better improve the level of the exhibition, to create a good brand image and obtain higher economic benefits; from the point of view of the exhibitors, exhibition evaluation is beneficial to the purpose of through the high level of display results improve the company's image, and achieve the goal of increasing sales to obtain high yield. For regulators and exhibition, exhibition evaluation is beneficial to its master the real level of the organizers and exhibitors, make different regulatory scheme.

\subsection{The Object and the Methods of the Evaluation}

At present domestic works related to the convention and exhibition industry in almost all the convention evaluation object is defined as the unit of exhibition projects, or convention and exhibition organizers. Unit on exhibition evaluation is annual assessment of performance and efficiency, and conference and exhibition organizers evaluation is about the size of the exhibition, the number of exhibitors and spectators, turnover, assessment of the economic and social benefits. Exhibition evaluation objects involved in the assessment method, sample size, sample structure, data acquisition method (generally uses the data collection, field investigation, questionnaire investigation and informal discussion meeting method), implementation process and problems of processing and data processing methods and tools, access to complete case seven aspects.

\subsection{The Exhibition Assessment Contents and Results}

Exhibition content of the assessment according to different evaluation objects are different, for meeting the evaluation content mainly includes topics and issues, participants, conference, time, place, reception, supporting activities, publicity activities and overall service quality evaluation sections. For participation evaluation mainly includes the purpose and effect, economic benefits, booth work three parts. Overall show evaluation around the exhibition theme, attendees, exhibitors and visitors, time, place, exhibits, booth, service, cost, clinch a deal the situation activities such as elements, involved in all kinds of business exhibition management, with strong professional.

Show the results of the assessment is the use of some statistical tables and diagrams in the form of the evaluation of information on after finishing, and the statistical charts to analyze trends, patterns and relations of description, related to the assessment result shows that, discussion and inference. Evaluation results are a reflection of the importance of the evaluation content and evaluation purposes.

\section{The Status of Chinese Exhibition Evaluation}

\subsection{Exhibition of the Assessment Law and the Status Quo of the Specification}

In 1993, after Chinese accession to "The Convention on the International Exhibition", exhibition industry development in our country will be mature. It is from the beginning of a blank in the eyes of the law to the relevant laws and norms of today, gradually improve the development of exhibition industry in China. In our country International level has been acknowledged and performed the convention on "International Exhibition" and "International Exposition League Rules", standard level in the industry, the former state economic and trade commission had issued the division of "the Professional exhibition level assessment "and other laws and regulations. Through the Internet and 400 journal of Chinese exhibition economy information (copy) for data collection, according to incomplete statistics, at present our country about the exhibition evaluation of national laws including foreign trade companies trade promotion office announced by the ministry of commerce of the foreign economic and "Technological Exhibitions in China Standards" and "Certification Assessment (try out) ", held the "Exhibition Certification Standards" and "the Detailed Rules for the Implementation of the Exhibition", "the Chinese Domestic Commercial Exhibition Assessment" and "Certification Measures (trial) ", "Chinese Exhibition Economy Research Institute of China Excellent Exhibition Project Evaluation Criteria and Method", "Chinese Exhibition Economy Research Institute of Chinese Convention and Exhibition City Exhibition Environment Assessment Standard and Method", "In the Measures for the Administration of Domestic Foreign Economic and Technological Exhibitions Held", "About Chinese and Foreign Economic and Technological Exhibition Evaluation Standards and Certification Method" and so on. Exhibition popular cities such as Dalian, Xiamen and other cities also introduced some local laws and standards, such as "Exhibition Service Selection Criteria in Dalian", "Dalian Exhibition Venues Service Selection Criteria", "Dalian City Professional Exhibition Service Competition Selection Table", "Dalian City 
Professional Exhibition Service Competition Selection Table", the "Trial Implementation Measures for the Xiamen Fair Assessment", "Xi 'an Exhibition Evaluation Index System" and so on.

\subsection{The Legal Status Quo}

At present, Chinese exhibition industry to cheat exhibition, the exhibition malignant events such as frequent, lack of famous provincial brand exhibition, exhibition, small scattered into the exhibition a big characteristic, blindly follow suit type for numerous repetitious exhibitions, brand construction strategy has increasingly become the means of exhibition will continue to develop, fair evaluation has become more and more big, the challenge is becoming more and more big. Are the achievements assessment but the exhibition in China in 2004 became the first to evaluate the fair in Wenzhou city and continue to maintain fair assessment; opened the exhibition in Shanghai in 2006, by the Shanghai exhibition industry review committee launched the exhibition project evaluation rules, shall be borne by the impartial third party assessment of actuators evaluation work, has strong authority; part of the exhibition project to join UFI, some international organizations, such as IAEM certification body. In recent years, with the continuous development of show business, first and second line of convention and exhibition cities such as Beijing, Xiamen also gradually introduced the exhibition evaluation with the relevant provisions of the treaty; many provincial or prefectural successively established convention and exhibition association and cross-regional exhibition union, to try and develop "exhibition festivals project evaluation" and "enterprise qualification evaluation of the exhibition", etc. But at the moment, the authority of national exhibition of appraisal institutions and comprehensive system of evaluation mechanism has not established, does not have Europe show national authoritative third party appraisal institution, the existing appraisal institution evaluation data and the result is true remains to be evaluate. Loopholes in exhibition evaluation situation chaos, data reporting, false to hide everywhere; because fair evaluation personnel to the organizer staff makes the evaluation process and results of easy influenced by internal factors; The government-led "claims the melon, puff" self-marketing evaluation method is acquisition main assessment practices, will not be able to effectively use intermediaries and neutral survey organization fair assessment; Heavy general data in the exhibition evaluation, missing "brand evaluation index" (visual), heavy conventional quantitative in the qualification assessment, lack of "visual (creative) ability evaluation", there is a similar phenomenon of "extensive" review is the present me a fair assessment of the situation.

In addition, China - Asean Expo, Yiwu Fair, Xian Garden Expo, the Shanghai world expo, Olympic Games in Beijing, Gao Jiaohui in Shenzhen, Guang Jiaohui in Guangzhou and so on level 1 expo will become Chinese major exhibitions, a rating agency, currently the focus of the evaluation object is not for all the show can do evaluation, assessment level also is much less than the foreign exhibition industry developed countries.

\section{The Chinese Exhibition Economy Research Information}

According to statistics, 400 issue of Chinese exhibition economy seminar information electronic journals of the communist party of China about 74 a fair assessment of articles/time, convention and exhibition of the reference information about the information of convention and exhibition research article 28/time. In the exhibition and evaluative article can be roughly classified into the following several aspects: about the properties of the exhibition scale, rating, and awards eight articles/time; obviously involves exhibition words in the post title evaluation of eight articles/time; (including exhibition service quality) and the quality of exhibition brand evaluation of 13 articles/time; qualification (mass) certification has 10 articles/time; for the exhibition scale, system and mechanism construction perspective in seven articles/time; to show the overall evaluation and project evaluation has seven articles/time; from the angle of the exhibitors and visitors to evaluate performance, angle to evaluate effect of exhibition, the exhibition and its evaluation for the expo each 2 articles/time; exhibition talents are also included in this assessment, the booth evaluation, show goodwill evaluation, evaluation methods and abroad exhibitions of emergency capability assessment, encountered in the emergency meeting assessment and quantitative evaluation of the exhibition articles 1 /time, the rest of the article involves the fair assessment, but does not carry on the systematic classification of six articles/time. Specific see table 1: 
Table 1.

Assessment Areas Involved Article Number (time/piece)

Percentage (\%)

\begin{tabular}{|c|c|c|}
\hline $\begin{array}{l}\text { Ratings, Appraisal and } \\
\text { Evaluation of the Rating }\end{array}$ & 8 & 10.81 \\
\hline $\begin{array}{l}\text { Heading is Exhibition } \\
\text { Evaluation }\end{array}$ & 8 & 10.81 \\
\hline Quality, Brand Evaluation & 13 & 17.57 \\
\hline $\begin{array}{l}\text { Qualification Certification } \\
\text { Assessment (mass) }\end{array}$ & 10 & 13.51 \\
\hline $\begin{array}{l}\text { Scale, Evaluation Systems } \\
\text { and Mechanisms }\end{array}$ & 7 & 9.46 \\
\hline $\begin{array}{l}\text { Exhibition as a Whole and } \\
\text { Project Evaluation }\end{array}$ & 7 & 9.46 \\
\hline $\begin{array}{l}\text { Expo Exhibitors, Audience, } \\
\text { Effect and Righteousness }\end{array}$ & 8 & 10.81 \\
\hline $\begin{array}{c}\text { Bits can be Classified } \\
\text { Assessment }\end{array}$ & 7 & 9.46 \\
\hline Other Assessment & 6 & 8.11 \\
\hline Total & 74 & 100 \\
\hline
\end{tabular}

In order to more intuitive understanding of the relevant articles in the percentage of the total articles times, figure 1 as shown below:

\section{Exhibition Economy Information to Assess Sexual Articles}

Classification Percentage

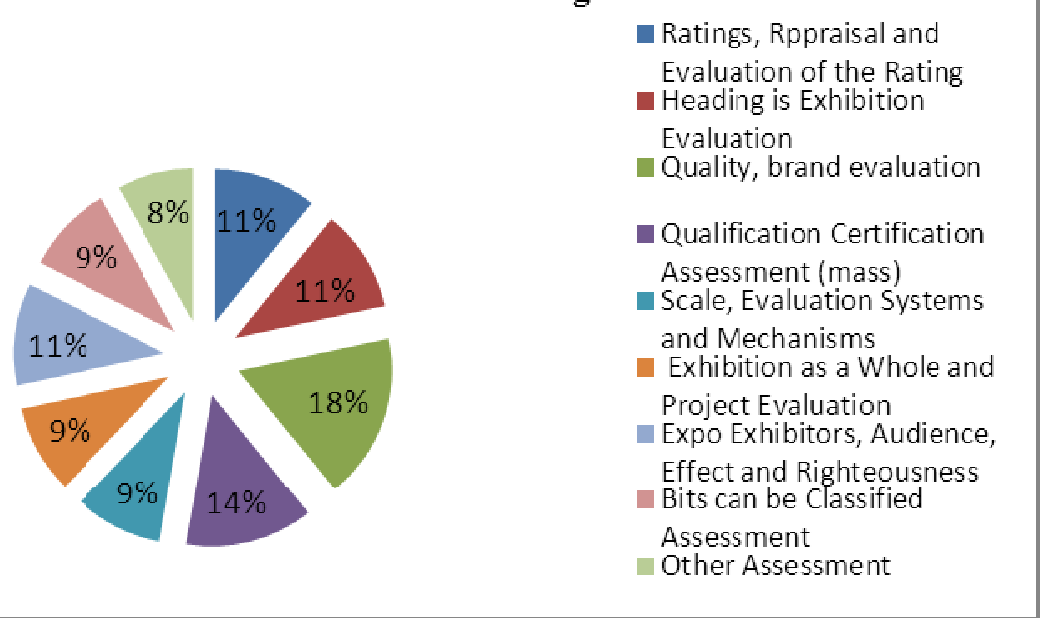

Figure 1.

At present, Chinese convention and exhibition is also in the development of conference and exhibition on the assessment is still in its early infancy, can see clearly from the table, the main focus on quality and brand, rating score and awards and qualifications (qualitative) research direction in the field of certification, etc. 


\section{The Conclusion and Countermeasures}

\subsection{From 400 in the Journal of Exhibition Economy Statistics}

From the results above, it is obvious that at present, Chinese convention and exhibition in the exhibition also evaluation work is still inadequate, in law didn't get enough support of relevant laws and regulations, still lacks a national laws about exhibition evaluation rules; and from the fair assessment on the popularity of the show, at present our country exhibition fair evaluation more focused on the national level, does not have universal applicability evaluation. An evaluation is still not mature enough, lack of mature, professional, independent and can be approved third party appraisal institution of the masses. From journal of exhibition economy information, it is very obvious can see China's convention and exhibition evaluation but mainly focus on quality and brand, rating score and awards (mass), and qualification certification, and other fields, the lack of detailed classification system of the professional exhibition evaluation, and evaluation in the field of awareness is not high, mainly rely on overseas UFI institutions, etc.

\subsection{Policy Recommendations}

Due to the convention and exhibition evaluation can improve the brand awareness of brand exhibition, exhibition industry to evaluate acquisition have larger demand. Fair evaluation not only increase brand awareness, at the same time also can guide enterprise law-abiding, standardized management, excellent industrial sustainable development support punish unqualified inferior industry, so as to improve the quality of the acquisition and development level, promote the rapid development of economy in China. To this end, the author thinks that to strengthen the construction of exhibition evaluation from the following several aspects:

Firstly, from a legal point of view, aiming at the shortcomings of the exhibition evaluation in our country law, advice exhibition institutions issued relevant local government more authoritative exhibition evaluation of laws and regulations, more specific and detailed rules for the stripe. At the same time, should have the authority of the national exhibition assessment regulations as soon as possible.

Secondly, from the perspective of the exhibition to evaluate attention, convention and exhibition in China should be in focus on the level of national exposition at the same time, strengthen the regulation of other fair evaluation work, on the quality of key fair assessment concerns over the quality of other exhibition at the same time constraints, can to a certain extent reduce the exhibition of cheat, crash happened.

Thirdly, from the perspective of the convention and exhibition evaluation in the field of view of the convention and exhibition in Chinese quality assessment, assessment area brand assessment and certification assessment mainly rely on foreign UFI agencies, local exhibition evaluation work is not authoritative, the reliability of the present situation, we must establish a reliable exhibition institutions of the third-party evaluation, and through the establishment of credit archives exhibition, exhibitors, the audience and the credibility of maintenance, to create brand reputation of the exhibition, and the construction of a harmonious expo exhibition market environment.

\section{References}

Baidu Library, http://baike.baidu.com/subview/18255/11191707.htm? Fr = Aladdin.

Cai Libin \& Tang Yuanyuan. (2009). Exhibition Evaluation Studies, Compulsory International Small Commodities Fair, For Example. Tourism BBS.

Chen Zeyan. (2007). Exhibition and Cultural Conception. Chinese Convention and Exhibition.

Feng Yue. (2013). Exhibition Evaluation Should not Lack Brand (visual) Evaluation. Chinese Exhibition Economy Seminar Information Electronic.

Gopalakrishna S, Lilien G L, Williams JD \& Sequeria I K. (1995). Do Trade Shows Pay off? Journal of Marketing. http://dx.doi.org/10.2307/1252121

Hansen K. (2004). Measuring Performance at Trade Shows Scale Development and Validation. Journal of Business Research. http://dx.doi.org/10.1016/S0148-2963(02)00269-2

Jing Chen. (2009). Discussed on Construction of City Exhibition Evaluation System. Journal of Marketing Research.

Kerin R A \& Cron W L. (1987). Assessing Trade Show Functions and Performance: An Exploratory Study. Journal of Marketing. http://dx.doi.org/10.2307/1251649

Li yunfang. (2007). The Present Situation of our Exhibition Project Evaluation Theory and Practice Analysis. Market Modernization. 
Liu Songping. (2004). From the International Furniture "Dongguan" ZhanKan Exhibition Effective evaluation. Journal of Advertising in China.

Ma Na, Shao Qiyong \& Yan Shaoqing. (2008). Chinese Exhibition Industry Standard System Framework to Build Research. World Standardization and Quality Management.

Qian Mengxiang. (2007). Jiangsu's Exhibition Industry Service Standard System Construction Discussion. Journal of Jiangsu Science and Technology Information.

Srinath Gopalakrishna \& Jerome D.Williams. (1992). Planning and Performance Assessment of Industrial Trade Shows: An Exploratory Study. International Journal of Research in Marketing. http://dx.doi.org/10.1016/0167-8116(92)90018-G

Sui Xin. (2006). Fuzzy Comprehensive Evaluation Technology in the Application of Fair Evaluation. In 2006, the First Chinese Exhibition Economy Research Institute Academic Essays.

The Economy Information Journal of Chinese Exhibition (electronic version), 2006 (1), 2014 (400).

Xu Chuanhong. (2004). Thinking about Chinese Exhibition Brand. Journal of Shanghai Engineering Technology University.

Xu Chuanhong. (2008). Theory of Exhibition Evaluation Problem of 5W. Chinaese Convention and Exhibition.

Yang Fangping \& Yu Ming Yang. (2010). Brand Exhibition Project Evaluation Index Based on AHP Study . Journal of Modern Management Science.

Yang Fangping. (2009). About Evaluation Index System of Brand Exhibition in a Preliminary Study. Journal of Shanghai Institute of Applied Technology (natural science edition).

Yang jie \& Gu yingkang. (2009). Selection and Evaluation Research Based on the Angle of the Exhibitors' Exhibition - 2007 Electronics Exhibition in Shanghai, For Example. Journal of Shanghai Institute of Applied Technology. 